\title{
FIBER BREAK MODEL FOR UNIDIRECTIONAL COMPOSITES IN TENSION-TENSION FATIGUE
}

\author{
Babak Fazlali", Stepan V. Lomov, Yentl Swolfs
}

\begin{abstract}
Department of Materials Engineering, KU Leuven Kasteelpark Arenberg 44 bus 2450, 3001 Leuven, Belgium
*babak.fazlali@kuleuven.be
\end{abstract}

Laminated composites are mostly used in structures under fatigue loading such as rudders and elevators in airplane and wind turbine blades. Different damage mechanisms such as fibermatrix debonding, fiber breakage, fiber fatigue, matrix cracking, delamination and their combination make it difficult to predict the behavior of laminated composites. Understanding the fatigue damage mechanisms at the microscale in unidirectional (UD) composites is vital to predict the fatigue behavior of laminated composites.

The current study considers Weibull statistics of fiber break, fiber fatigue, fiber-matrix debond growth, matrix cracking and matrix plasticity as the fatigue damage mechanisms in UD and is based on ideas of a model for fiber breaks under quasi-static loading [1]. A random fiber 2D packing is generated [2] and extruded in the fiber direction, and considered as a representative volume element of UD composites. Each fiber is $5 \mathrm{~mm}$ long and is divided into elements, each having a length equal to the fiber radius. The strength is assigned to each element using a unimodal Weibull distribution. The Weibull parameters are representative of T700 carbon fibers [3].

The predicted fatigue life of UD composites is presented in Figure 1. Considering a 25\% fatigue reduction in fibre strength, leads to a $17 \%$ reduction in the composite fatigue resistance. This means that the fatigue resistance of composites is better than the fibers. Considering debond growth as the only damage mechanism in fatigue yields a $12 \%$ fatigue reduction and the combination of $25 \%$ fiber fatigue with fiber-matrix debond growth causes a $21 \%$ fatigue strength reduction. We therefore conclude that the synergetic effect of different damage mechanisms is additive but significantly lower than the linear summation.

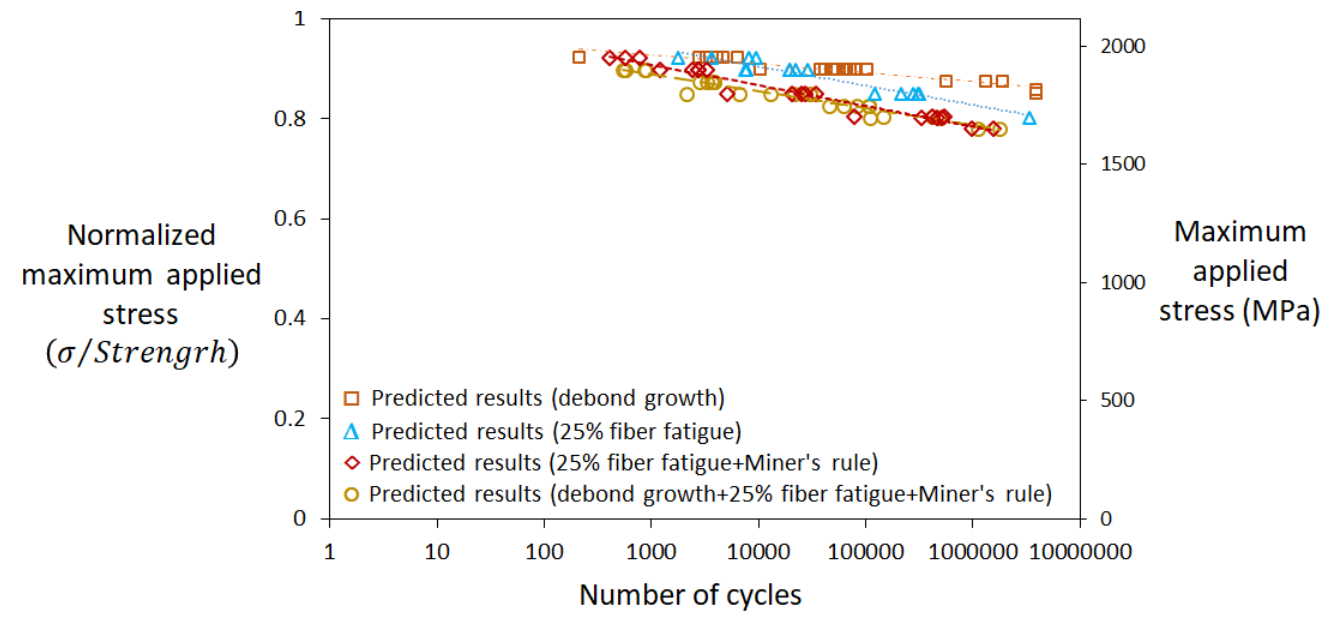

Figure 1. S-N curves of UD T700/epoxy composite in tension-tension loading

\section{References}

[1] Swolfs, Y., R. M. McMeeking, I. Verpoest and L. Gorbatikh (2015) Matrix cracks around fibre breaks and their effect on stress redistribution and failure development in unidirectional composites. Composites Science and Technology 108: 16-22.

[2] A. R. Melro, P. P. Camanho, and S. T. Pinho (2012) Generation of random distribution of fibres in long-fibre reinforced composites. Compos. Sci. Technol., 68, 2092-2102.

[3] Y. Swolfs, I. Verpoest, and L. Gorbatikh (2015) Issues in strength models for unidirectional fibre-reinforced composites related to Weibull distributions, fibre packings and boundary effects. Compos. Sci. Technol., 114, 42-49. 